\title{
Research of the Hydrodynamic Characteristics of Ocean Spar Sea Station
}

\author{
W.B. Xu \\ Faculty of Maritime and Transportation \\ Ningbo University \\ China
}

\author{
K.Q. Zhu \\ Faculty of Maritime and Transportation \\ Ningbo University \\ China
}

\author{
Y.C. Miao \\ Hudong-Zhonghua Shipbuilding (Group) Co., Ltd. \\ China
}

\begin{abstract}
The ocean spar sea station has not been widely applied in our country, but its good ability to resist deformation and characteristics of subsidence made it has an irreplaceable role in the deep water. If one deep sea cage can be developed with independent intellectual property rights on the basis of the sea station, it will have a significant impact on our country's aquaculture. In this paper, a single grid mooring sea station cage numerical model is built based on the lumped-parameter method and calculated under different sea conditions with OrcaFlex. Results show that under the combined wave-current action, the forces on mooring lines are strongly influenced by current velocity, followed by wave height and are hardly influenced by the period of waves. The maximum tension of the mooring lines occurs when the wave and current have a certain angle, rather than under parallel wave-current conditions. The maximum float rim pitch increases linearly as the flow velocity and wave height increase, and decreases as the period of the waves increase. In addition, the forces on cage and mooring lines may decrease obviously when the cage is submerged.
\end{abstract}

Keywords-ocean spar sea station; mooring line; hydrodynamic characteristic

\section{INTRODUCTION}

The exhaustion of marine fishery causes a lot problem due to the overfishing and offshore marine environment pollution. Deep water aquaculture cage is the world's coastal development strategy of marine economy, which also is important strategic need of our country modern agriculture to develop the field of marine in the new period. At present, the gravity cage is more suitable for China's national conditions. Actually this cage is the most used which structure is simple, management is more convenient and the price is relatively low. Although the floating gravity cages are widely used, but it is also limited by some inevitable problems, such as the apparent effects of strong water flow, the severe drift of nets, high loss rate of the cage's volume. The loadings on the net increase while we need to keep the shape unchanged at the same time, this is easy to cause net tear. Therefore, in the sea where the flow velocity is large, the use of it is limited. So it is also necessary to understand and study the advanced cages, typically for A merican Sea Station Cage, also known as fly ing saucer type submersible large-scale deep water cage. There are many achievements of relevant studies about gravity cages about numerical simulation and model experiment at home and abroad [1-7], but so far there is only relatively detailed structure introduction and a preliminary estimate of hydrodynamic for sea station in the domestic. Li [8, 9] also just conduct some model experiments, but their work is very important and significant for this report. This paper build the sea station model with OrcaFlex based on the lumpedparameter method. Analysis the mechanical characteristics of the cable and movement of the cages under the joint action of wave and sea flow by numerical simulation, attempting for further understanding of the hydrodynamic characteristics of the cage, and providing some reference for the study of sea station and its mooring system.

\section{NUMERICAL MODEL}

This research object of this article is sea station cage. The offshore net pen/mooring system analysed consists of a central spar cage and a submerged mooring grid. The cage is a semi rig id structure constructed around a centre spar buoy. Nets and radial spoke lines are held in tension between the spar buoy and an octagon shaped rim. The rim of the cage has a nominal diameter of $15 \mathrm{~m}$ and is made of eight flanged sections of steel pipe. Each of the flanged sections are individually sealed and pressurized. A variable buoyancy chamber with a length of $3.16 \mathrm{~m}$ inside the spar buoy enables the entire cage to be submerged to a specific operating depth determined by the length of the ballast weight attachment line. Lines with compensator buoys connect the cage to the grid at the four nodal locations, and the cage is located in the middle of each grid square. The grid is anchored to the bottom using four mooring legs each incorporating a chain centenary. Tension is maintained by using flotation at the four nodal points at the top of the grid and by setting the anchors to form the required geometry. The central spar cage can be submerged by ballasting a variable buoyancy chamber in the spar buoy. In many applications, the cage is submerged to avoid structural and biological damage during harsh sea conditions or to provide suitable fish-growing environment. The dimensions of the cage, mooring system and buoy as well as the cages connection details can be seen in references. In this paper, a 
real cage model is built based on the lumped-parameter method by professional hydrodynamic analysis software OrcaFlex, as shown in Fig. 1. Some basic theory about lumped-parameter method can refer to Zhu [3] and other's work. As the main content of this study is the entire cage and the hydrodynamic response of the mooring system, so the connection between the various components are simplified, such as all rope connection are simplified as pin joint. This article don't model real force on net and choose commonly used Airy wave theory and uniform flow in various combinations to impose different environment load on aquaculture system in order to decrease computation time at the same time, so the results of the research have certain reference value.

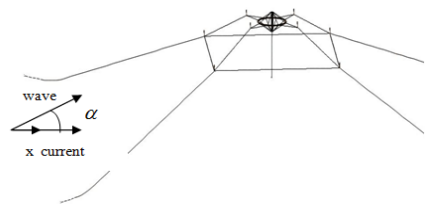

FIGURE I. THE NUMERICAL MODEL OFT HE CAGE

\section{RESULT AND ANALYSIS}

In the deep sea area, there is often bad weather such as typhoon, and the waves and currents will appear at the same time in this case. The mooring system will limit the movement of the cage to ensure the safety of the construction and fish. Under the combination action of wave and currents, the tension of the mooring line will reflect force of the whole structure of the cages to some extent. Once the mooring system failu re, not only will cause the fish escape and death, it will also cause serious damage to the construction, and bring huge economic losses for farmers. So the research on the safety of the mooring system is necessary. In this paper, we study a variety of combination of waves and currents, including three wave height $(2 \mathrm{~m}, 4 \mathrm{~m}, 6 \mathrm{~m})$ and three periods $(6 \mathrm{~s}, 9 \mathrm{~s}, 12 \mathrm{~s})$ and four kinds of velocity (from $0 \mathrm{~m} / \mathrm{s}$ to $2 \mathrm{~m} / \mathrm{s}$ ). It is important to note that the software the default wave and current direction is $180^{\circ}$. The Fig. 2 shows under the action of the pure wave, the relationship between the maximum tension of the mooring line in the front and the wave period and wave height. The figure shows that, when the period is unchanged, the mooring line tension roughly change linearly with wave height linearly under the action of the pure wave; when the height of wave is unchanged, the relationship between the period and mooring line tension is not obvious, the mooring line tension almost remain the same when the period is large.

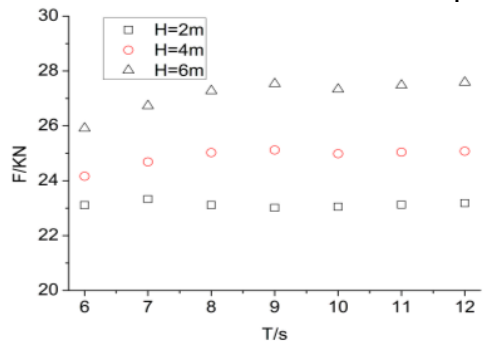

FIGURE II. MAXIMUM MOORING LINETENSION FOR A SINGLECAGE SYSTEM INDUCED BY VARIOUS WAVES
Fig. 3 shows maximum tension in the front mooring line of a single-cage system under combined various wave-current conditions. According to fig. 3a-c, the wave period is longer, velocity of flow at the same time, the same high wave cages mooring line tension is almost the same maximum. When the wave period is the same (fig. $3 \mathrm{~d}-\mathrm{f}$ ), the greater of the wave height, and the maximum value of tension of anchor line is bigger. And with the increase of flow velocity of uniform, a maximum of mooring line tension is not linear increase, but increase faster and faster. Comprehensive contrast all figures mentioned above can be found in the study of this paper, the effects of the wave's parameters on the cages of mooring line tension affect the importance of the largest in the order: velocity $\mathrm{V}$, wave height $\mathrm{H}$, period $\mathrm{T}$.

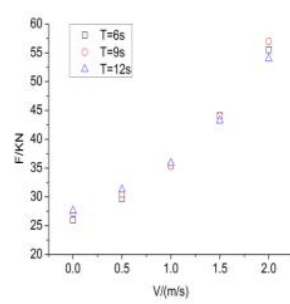

(a) $\mathrm{H}=2 \mathrm{~m}$

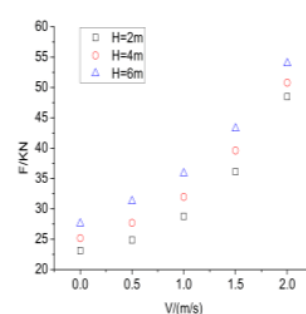

(d) $\mathrm{T}=6 \mathrm{~s}$

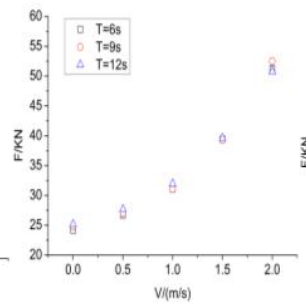

(b) $\mathrm{H}=4 \mathrm{~m}$

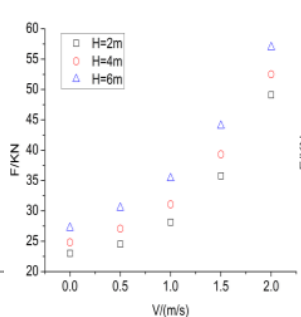

(f) $\mathrm{T}=12 \mathrm{~s}$

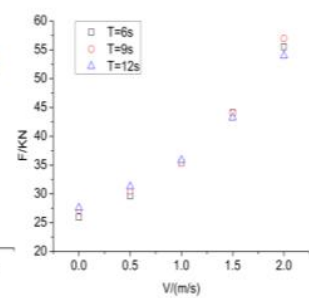

(c) $\mathrm{H}=6 \mathrm{~m}$
FIGURE III.

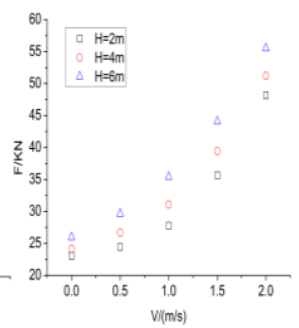

(e) $\mathrm{T}=9 \mathrm{~s}$ BY VARIOUS WAVE-CURRENT CONDITIONS

For the submerged cage, it is a important way to quickly sink to the bottom of the sea to ensure the safety when encountered the typhoon. So the force of the cages sinking, limit sea condition is also very necessary. In the deep sea wave and current direction is not always the same, in order to study the oblique incident wave and current effect on the anchor rope tension, we assume that the uniform flow only along the $\mathrm{x}$ axis direction, but wave incident angle is different.

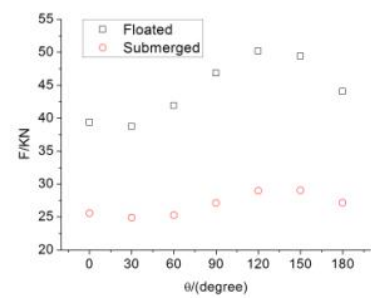

FIGURE IV.

MAXIMUM MOORING LINE TENSION INDUCED BY DIFFERENT INCIDENT WAVE ANGLE

Fig. 4 is in uniform velocity of $1.5 \mathrm{~m} / \mathrm{s}$, to meet with surface tension of anchor rope biggest and incident wave $(\mathrm{H}=6 \mathrm{~m}, \mathrm{~T}$ $=9 \mathrm{~s}$ ) the relationship between Angle of forward. You can see by the picture, anchor rope tension as the change of incident 
wave angle is one of the biggest periodic variation; Higher than when the flow wave flow reverse when the anchor rope tension, but the maximum tension occurs in wave under the condition of about $120^{\circ}$ angle; And can be seen from the diagram, the sinking area can obviously reduce the stress of the anchor rope, in this case the cages to sink can make the anchor rope stress reduced by $35 \% \sim 43 \%$.

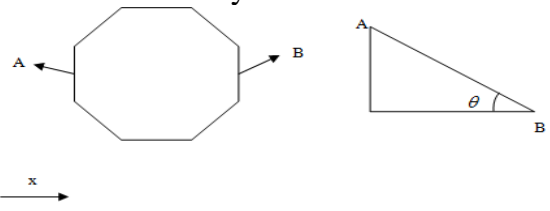

FIGURE V. FLOAT RING INCLINATION CALCULATION DIAGRAM

As shown in fig. 5, floating ring on both sides of the midpoint of $\mathrm{A}$ and $\mathrm{B}$, assuming that the floating ring rotation and deformation under the joint action of wave amplitude is small, the floating ring overall angle can be through A, B two attachment and the angle between the horizontal line. This paper calculates the different wave flow cases cages floating ring maximumangle, as shown in the figure below:
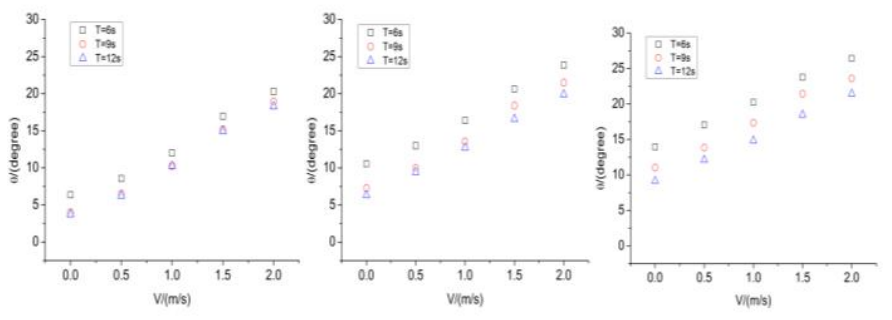

(a) $\mathrm{H}=2 \mathrm{~m}$

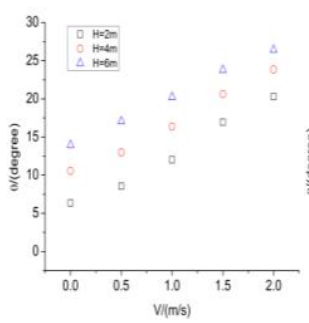

(d) $\mathrm{T}=6 \mathrm{~s}$

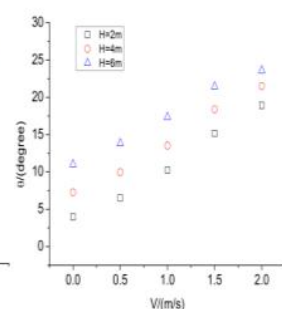

(b) $\mathrm{H}=4 \mathrm{~m}$

(C) $\mathrm{H}=6 \mathrm{~m}$

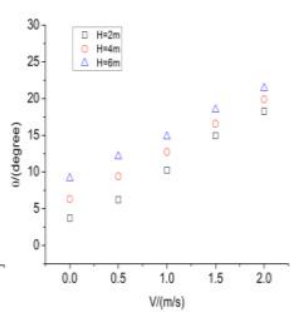

(e) $\mathrm{T}=9 \mathrm{~s} \quad$ (f) $\mathrm{T}=12 \mathrm{~s}$
MAXIMUM FLOAT RING ANGLE INDUCED BY VARIOUS WAVE-CURRENT CONDITIONS

The fig. 6a-c shows that wave higher timing, floating ring angle and velocity is roughly linear relationship. Period is small (6 s), the floating ring tilt angle will be significantly larger; under the same flow rate, the period is bigger, wave height is small ( $9 \mathrm{~s}$ and $12 \mathrm{~s}, 2 \mathrm{~m}$ and $4 \mathrm{~m}$ ) floating ring angle difference is small, but this difference will be increased with the increase of flow velocity increases gradually. From Fig. $6 \mathrm{~d}-\mathrm{f}$, the period must be, floating ring tilt angle and velocity of a linear relationship, increases with the increase of wave height, but increase the amplitude decreases with the increase of flow rate and period.

\section{CONCLUSION}

In this paper, a real cage model is built based on the lumpedparameter method by professional hydrodynamic analysis software OrcaFlex, a preliminary attempt for the first time modelling this complex system in $3 \mathrm{~d}$ visualization method. But there still are a lot of the details such as the loading on the net, need to be specified in later work. In spite of this, the conclusions we get are basically the same with the conclusion get from model experiment reported by the reference. So we could think the numerical model has certain reliability. So me mainly conclusions can be summarized as the following:

(1) Under the action of the pure wave, when the period is unchanged, the mooring line tension roughly change linear with wave height linearly under the action of the pure wave; when the height of wave is unchanged, the relationship between the period and mooring line tension is not obvious, the mooring line tension almost remain the same when the period is large.

(2) Under the combination action of wave and current, the wave period is longer, the maximum mooring line tension is almost the same; if wave period is the same, when the wave height is greater, and the maximum mooring line tension is greater.

(3) When the current direction is certain, maximu mooring line tension changes with the incident angle of wave; the movement and mooring line tension can reduce significantly when the cage is submerged.

\section{ACKNOWLEDGEMENT}

Funding for this work was provided by the National Natural Science Foundation of China. (Grant No. 11272160).

\section{REFERENCES}

[1] Fredriksson D W, Muller E, Baldwin K, et al. Open ocean aquaculture engineering: system design and physical modelling. Marine Technology Society Joumal, 34(1), pp. 41-52, 2000.

[2] Tsukrov I I, Ozbay M, Swift M R, et al. Open ocean aquaculture engineering: numerical modelling. Marine Technology Society Journal, 34(1), pp. 29-40, 2000.

[3] ZHU Ke-qiang, CAI Ying, YU Chun-ling, ZHENG Dao-chang et al. Nonlinear Hydrodynamic Response of Marine Cable-Body System Undergoing Random Dynamic Excit ation. Joumal of Hydrodynamics, 21(6), pp.851-855, 2009,

[4] Huang C C, Tang H J, Liu J Y. Effects of waves and currents on gravity-type cages in the open sea. Aquacultural Engineering, 38(1), pp. 105-116, 2008.

[5] Fredriksson D W, Irish J D, Swift M R, et al. The heave response of a central spar fish cage. Joumal of Offshore Mechanics and Arctic Engineering, 125(4), pp. 242-248, 2003.

[6] Tsukrov I, Eroshkin O, Fredriksson D, et al. Finite element modelling of net panels using a consistent net element. Ocean Engineering, 30(2), pp. 251-270, 2003.

[7] Fredriksson D W, Muller E, Baldwin K, et al. Open ocean aquacult ure engineering: system design and physical modelling. Marine Technology Society Joumal, 34(1), pp. 41-52, 2000.

[8] Li Y, Gui F, Teng B. Hydrodynamic behaviour of a straight floating pipe under wave conditions. Ocean engineering, 34(3), pp. 552-559, 2007.

[9] Zhao Y P, Li Y C, Dong G H, et al. An experimental and numerical study of hydrodynamic characteristics of submerged flexible plane nets in waves. Aquacultural engineering, 38(1), pp. 16-25, 2008. 